\title{
RECENT DEVELOPMENTS IN DRY SLAG GRANULATION: A PATH TO IMPROVING SAFETY AND SUSTAINBILITY OF THE METALLURGICAL SECTOR*
}

Santiago Faucher ${ }^{1}$ Sina Mostaghel ${ }^{2}$ Lily Lai Chi So ${ }^{3}$ Sang Yoon $\mathrm{Oh}^{4}$

\begin{abstract}
Molten slag from pyrometallurgical furnaces is tapped at high temperature, carrying a large amount of thermal energy. But the common slag dumping and water granulation methods used for slag treatment do not permit energy recovery. Furthermore, water is present in these processes and while operations are designed to minimize risks of steam explosions, from the contact of slag with water, these common slag handling practices have never been inherently safe. Common handling practices do permit some slags to be sold, but often in low volumes at low prices. Dry granulation offers advantages over these common slag handling practices, including the production of by-products, the recovery of thermal energy, and the eliminated consumption and safety hazards of water. For these reasons, there have been various studies in dry granulation and heat recovery, but most have never been brought to commercial scale due to scalability and cost challenges. EcomaisterHatch has developed and brought to commercial scale a reliable and simple dry granulation and heat recovery technology. Here we review common slag handling practices, the developments in dry slag granulation over the last three decades, introduce the Ecomaister-Hatch dry slag granulation process, and elaborate on future applications of the technology in the processing of argon oxygen decarburization and blast furnace slags.
\end{abstract}

Keywords: Dry slag granulation; Atomization; Energy recovery, Steam explosion.

1 Global Director, Technology Development, Hatch Ltd., 2800 Speakman Drive, Mississauga, Ontario, Canada L5K2R7.

2 Metallurgist, Technology Development, Hatch Ltd., 2800 Speakman Drive, Mississauga, Ontario, Canada L5K2R7.

3 Process Engineer, Technology Development, Hatch Ltd., 2800 Speakman Drive, Mississauga, Ontario, Canada L5K2R7.

4 CEO, Ecomaister Co. Ltd., 104, 250, Geonjiro, Seo-Gu, Incheon, Korea. 


\section{INTRODUCTION}

Slag has traditionally been regarded as an undesired waste in the iron and steel industry, with slag management focused on removal and disposal of "waste". Typical slag management methods include dumping and water granulation. Electric arc furnace (EAF), ladle metallurgy furnace (LMF), argon oxygen decarburization (AOD), and blast furnace (BF) slag is dumped onto the ground, left to cool and solidify into crystalline solid, after which it is broken up and handled by heavy machinery. Water granulation is sometimes applied to BF slag. It involves quenching, fragmenting, and granulating molten slag with water. The resulting granulated slag is glassy in structure and is easier to handle then dumped slag as handling can be done cold with less wear and tear on machinery.

These processes present significant safety risks to operators and equipment handling slag. Although significant engineered safety devices are installed in these operations, they are not sufficient to protect against the explosive results of water and slag mixing, which can occur due to environmental conditions, equipment malfunction, and/or human error. Examples of these incidents have been reported repeatedly [1-5]. It is evident that the presence of water, by design or by environment, in traditional slag handling methods results in conditions that are not inherently safe.

We must therefore develop and implement safer techniques that can treat slag in the absence of water. Dry slag granulation addresses not only the safety risks, but also the environmental and sustainability challenges associated with traditional slag dumping and water granulation methods.

\section{ANALYSIS AND COMPARISON OF SLAG HANDLING METHODS}

Slag handling methods can broadly be classified into three categories: (1) dumping and slow cooling, (2) wet granulation, and (3) dry granulation.

\subsection{Dumping and Slow Cooling}

Slag dumping involves hauling and transportation of slag to designated pits, where the slag is dumped and left to solidify and cool. Depending on the quantity of slag, it can take several hours to several days to cool. Once the slag is sufficiently cooled to handle, powerful front end loaders capable of breaking the slag are used to excavate the pit. Although the loaders are typically equipped with bullet proof and metal screened windshields, chained tires, and tire fire suppression systems, it is common to see front end loaders with tires on fire or with cracked windshields, indicative of the conditions that this equipment is subjected to. For these same reasons, these heavy duty fuel consuming vehicles typically have short working lives and are depreciated over 3 to 5 years. To facilitate the work of the front end loader and to permit slag cooling and breakup, water sprays are often used. The elements for slag-water explosions are therefore present by design and also from weather conditions and the open space under which these operations are undertaken. After cooling and preliminary breakup, the slag is often crushed and sent to separators for metal recovery.

Although slag dumping is widely used to handle blast furnace (BF), basic oxygen furnace (BOF), electric arc furnace (EAF), ladle metallurgy furnace (LMF), and argon oxygen decarburization (AOD) slags, there are remarkable challenges with this method. Firstly, slag hauling requires high capital and operating costs due to its need 
for high-temperature-resistant slag handling equipment (e.g. slag pots, slag pot haulers, front end loaders) and their maintenance costs. This process is also labour intensive, with molten slag handling being a safety risk for operators. Secondly, the dumped slag in the environment leads to risks of leaching hazardous elements into ground water. Thirdly, the crushing, loading, and transporting of slag results in numerous dust emission sources and increased energy consumption for mobile machinery. Further, slag heat recovery is not possible due to the release of thermal energy to ambient environment. Lastly, crushed slow air-cooled slag has a crystalline structure with limited applications, typically as low-value construction aggregates, which is a challenge especially for BF slag. Some slow air-cooled slag is also prone to dusting, posing environmental risks and limiting its application as a by-product, which is a challenge for LMF and AOD slags.

\subsection{Wet Slag Granulation}

Wet granulation is used in a number of smelters to handle BF slag. Wet granulation uses water to fragment and quench the molten slag. The slag is first granulated via launder granulation and tank granulation. In launder granulation, molten slag is granulated and quenched with pressurized water jets. In tank granulation, molten slag is directly poured into large quantities of stirring water. The slag/water slurry is then dewatered and dried such that the water content in the granulated slag is reduced to acceptable levels for storage, landfill, or slag sale.

Wet granulation addresses some of the challenges of slag dumping, such as molten slag hauling and production of higher value by-product. Wet granulation allows for fast quenching of molten slag and production of high value glassy material, which, for BF slag, demonstrates desirable cementitious properties post milling. BF slag is typically devoid of metal, making water granulation a manageable process from a safety perspective. However EAF, BOF, LMF, and AOD slags contain some amount of metal, with LMF and AOD slags containing as high as $50 \%$ by weight metal, making water granulation a risky and non-viable proposition for these slags.

Although wet granulation demonstrates some benefits over slag dumping, it has its own set of challenges. Firstly, the combination of water and slag can lead to steam explosions, posing a significant safety risk. Engineered devices, such as thick steel plates, typically enclose the granulation areas so that the explosions that occur do not result in great damage. Nonetheless, loss of life is known to occur. Another safety concern is the generation of $\mathrm{H}_{2} \mathrm{~S}$ gas which is detectible by smell even at low concentration and the corrosion damage $\mathrm{H}_{2} \mathrm{~S}$ causes to surrounding infrastructure. $\mathrm{H}_{2} \mathrm{~S}$ also acidifies the water, and with the presence of residual metals in the slag, contributes to leaching of these elements into the wastewater, requiring downstream water purification. Secondly, capital cost of wet granulation systems are relatively high due to higher complexity in system design (e.g. water reservoirs, cooling towers, water purification, and $\mathrm{H}_{2} \mathrm{~S}$ scrubbing systems) and size of equipment. Wet granulation also typically demands higher operating costs due to water consumption (typically 10 tonnes of water is required per tonne of slag, one tonne of which is evaporated), high equipment maintenance (due to abrasiveness of slag/water slurry), and energy consumption (due to need for slag drying). As such, wet granulation is a costly process in the metal producers' flow-sheets. 


\subsection{Dry Slag Granulation}

Significant research and development has occurred in the area of Dry Slag Granulation (DSG) over the past decades. Development of DSG technologies is driven by the desire to improve safety and sustainability of conventional slag handling methods. The most significant advantage of DSG is that it provides a safer and more environmentally friendly method for slag handling compared to conventional methods. There are no risks of steam explosion as water, one of the key ingredients for such explosions, is eliminated. Risks of leaching environmentally concerned elements into groundwater are also reduced as the slag is not "washed" by water. In addition, minimized handling and transportation of molten material minimizes risks of accidents for operators. Another advantage of DSG is the lower capital and operating costs compared to conventional processes due its simple design and the limited equipment in contact with molten material. In addition, physical and chemical properties of dry granulated slag may be controlled to produce high-value slag products with various applications. This combination can provide a unique slag byproduct handling process that returns value to the metal producers permitting a lowering of their metal production cost. Further, DSG can allow heat recovery from the molten material (hot air, and/or electricity), which can improve the overall energy efficiency of the pyrometallurgical operations, reducing its energy consumption and $\mathrm{CO}_{2}$ emissions.

DSG methods can broadly be categorized as: (1) mechanical granulation, where molten slag is broken up and quenched via mechanical means, such as rotating drums, blades, or shot material, (2) centrifugal granulation, where molten slag is ejected radially outward via centrifugal force, during which it is broken up into small droplets and quenched into solidified granules, and (3) air atomization, where air impinges on the molten slag flow breaking up the slag into droplets and quenching the droplets into solidified granules.

\subsubsection{Mechanical Granulation}

\section{Baosteel Short Slag Treatment Facility (BSSF)}

Baosteel started to develop the BSSF process for steelmaking slag in the mid 1990s. Molten slag is treated in a revolving container where mechanical force from impinging steel spheres and cooling from water sprays produces crushed solidified slag. A number of steel works has adopted this process, including Baosteel, Masteel, POSCO, and JSW [6,7]. In principle, this technology is not a dry process, but a semiwet/dry process. Water is used which leads to internal "explosions" within the machinery. Nonetheless, BSSF has received some attention and implementation.

\section{Paul Wurth Steel Sphere Injection}

In 2013, ROGESA implemented a full-scale pilot plant on their blast furnace BF4 using the Paul Wurth steel sphere injection system [8]. The plant includes slag caster with steel sphere injection and is designed to handle 8 tonnes/min of liquid BF slag. In Phase 1, the pilot plant demonstrated that the system can safely and reliably solidify slag while producing slag with high glass content. As of July 2014, the maximum slag flow rate of 8 tonnes/min has been reached and safely solidified. Glass content of up to $92 \%$ has been measured, but has not yet been achieved consistently. In Phase 2, potentials for heat recovery will be investigated. The hot 
ingot of slag and spheres will be transferred to a heat exchanger, where energy from the mixture is transferred to hot air at a temperature of approximately $600^{\circ} \mathrm{C}$.

\subsubsection{Centrifugal Granulation}

\section{Siemens VAI Spinning Cup Granulation}

Siemens VAI has scheduled for implementation of an industrial-scale pilot plant at VoestAlpineStahl for 2015 [9]. BF slag is poured onto the center of a high speed rotating cup and is ejected radially outward to form glassy granules with over $95 \%$ glass content. The slag falls into a modified fluidized bed, where waste heat is estimated to be recovered at $400^{\circ} \mathrm{C}$, or possibly up to $650^{\circ} \mathrm{C}$ after optimization.

\section{CSIRO Spinning Disk Granulation}

CSIRO began development of this technology in 2002. Molten slag is poured onto the center of a high speed spinning flat disk and is ejected radially outward to form droplets. Major technological advances were made to allow for rapid quenching of slag particles within a compact reactor while allowing for heat recovery [10]. In March 2015, the Beijing MCC Equipment Research \& Design Corporation agreed to demonstrate this technology at industrial scale for BF slag handling [11]. This system enables glassy slag product to be extracted, along with $500-600^{\circ} \mathrm{C}$ hot air.

\subsubsection{Air Atomization}

\section{Ecomaister-Hatch Air Atomization Technology}

A schematic of the commercial-scale Ecomaister-Hatch air atomization technology is provided in Figure 1. Molten slag discharged from the furnace is conveyed to a slag feeding chute located in front of an atomization chamber either via slag launders or by slag pots. An air jet granulates and quenches the molten slag into the atomization chamber, as shown in Figure 2a. Inside the chamber, the granulation air passes cocurrently to the hot granules to cool the granules and to obtain a hot gas stream. The cooled and solidified granules, shown in Figure $2 b$ to Figure $2 e$, can be periodically collected or continuously conveyed out of the chamber to be packaged for storage or sale. The recovered hot gas is directed to off-gas cleaning or to equipment that uses this energy.

Air atomization is a relatively simple process as no machinery comes into contact with molten slag, therefore reducing equipment damage, equipment failure, and their associated safety risks. As such, this technology has been widely adopted and is applied to process ferrous (EAF, BOF, and LMF) and non-ferrous (zinc and silicomaganese) slags at the commercial scale. In addition, heat recovery has been implemented at two non-ferrous sites. There is on-going development in the atomization of BF, AOD, and non-ferrous slags, and in incorporation of slag heat recovery into metallurgical plants. The major advantages of this technology include improved slag handling safety, slag heat recovery, reduction in costs of slag handling, and production of high-value slag products, which will be discussed in detail in the subsequent section. 

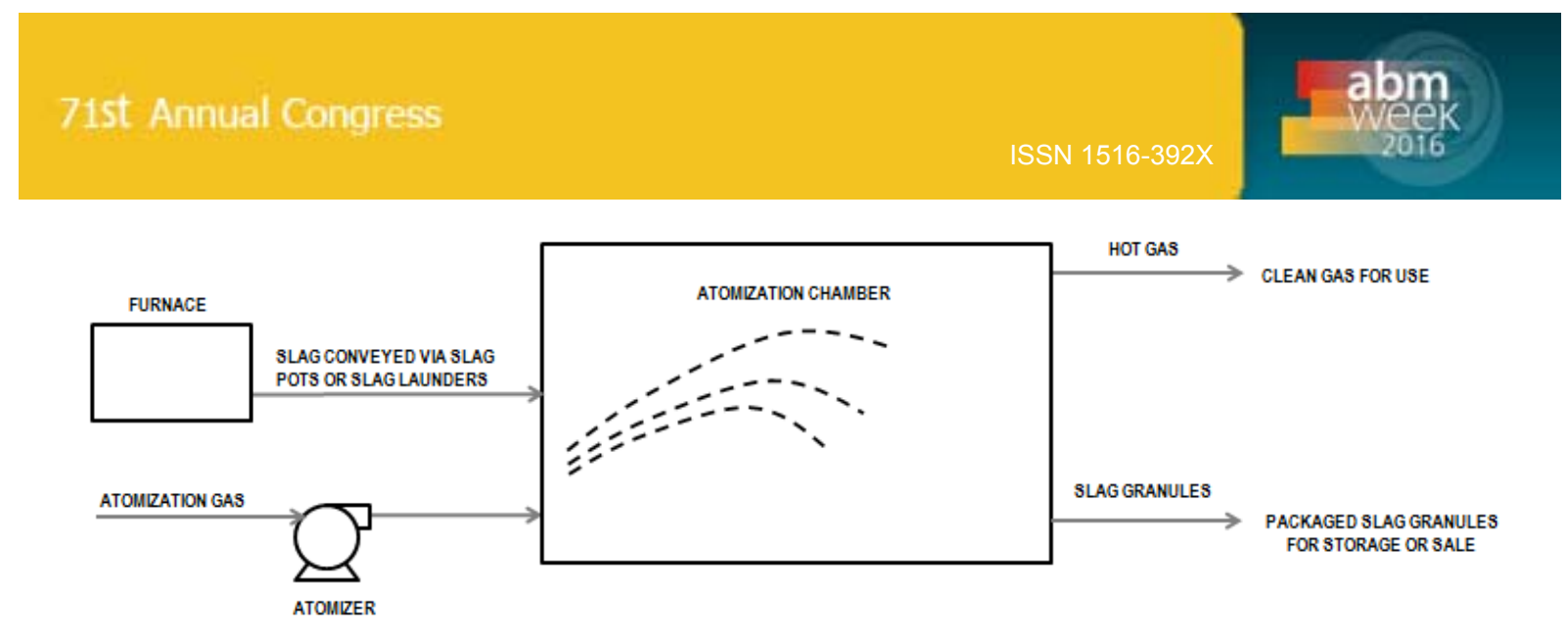

Figure 1. Schematic process flow diagram of the Ecomaister-Hatch air atomization technology
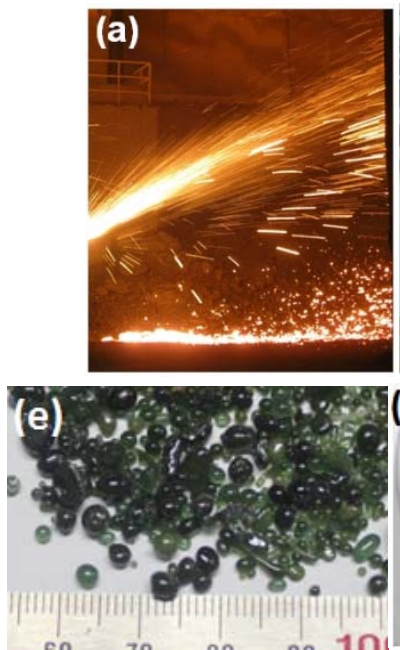
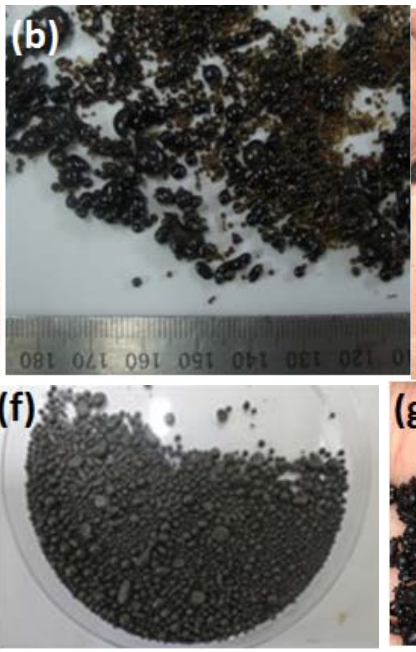

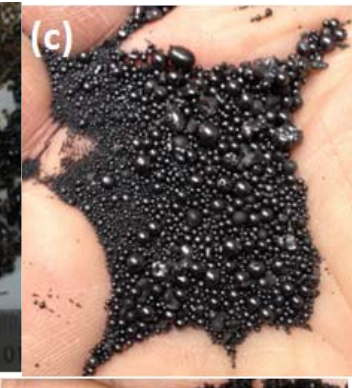

(g)

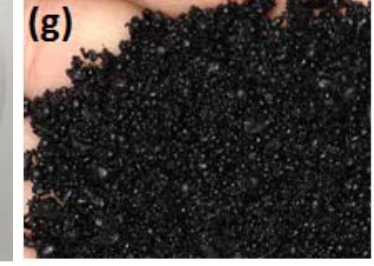

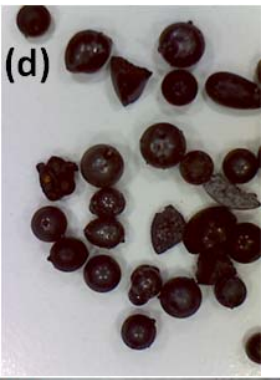

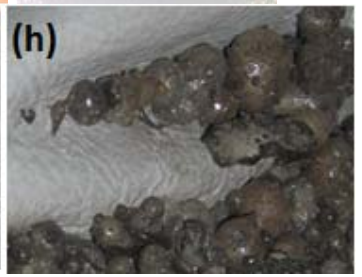

Figure 2. (a) Current commercial operation of Ecomaister-Hatch Air Atomization Technology, (b) atomized BF slag, (c) atomized BOF slag, (d) atomized EAF slag, (e) atomized LMF slag, (f) atomized AOD slag, ( $\mathrm{g}$ ) atomized zinc slag, and (h) atomized silicomanganese slag

\section{ATOMIZATION APPLIED TO IRON AND STEEL SLAGS}

\subsection{Current Applications}

The Ecomaister-Hatch air atomization technology has been widely applied on the commercial scale for treating EAF, BOF, and LMF slags. Atomization improves safety of slag handling and allows for reduction in slag handling costs, it also allows for the production of useful high value slag products through stabilization of slag.

\subsubsection{EAF and BOF Slags}

Conventional handling of EAF, BOF, and LMF slag involves dumping and slow cooling. Dumped and slow cooled EAF and BOF slags are typically used as construction and pavement aggregate. However, the feasibility of using EAF and BOF slags in these applications highly depends on their volume stability. Volume instability stems from the presence of free calcium oxide $(\mathrm{CaO})$ (lime). Slow cooling allows for the transition of tricalcium silicate $\left(\mathrm{Ca}_{3} \mathrm{SiO}_{5}\right)\left(\mathrm{C}_{3} \mathrm{~S}\right)$, into dicalcium silicate, $\left(\mathrm{Ca}_{2} \mathrm{SiO}_{4}\right)\left(\mathrm{C}_{2} \mathrm{~S}\right)$, and $\mathrm{CaO}$. In the presence of water, free $\mathrm{CaO}$ hydrates and forms calcium hydroxide $\left(\mathrm{Ca}(\mathrm{OH})_{2}\right)$, which has a lower density than $\mathrm{CaO}$ and, hence, hydration of free $\mathrm{CaO}$ results in volume increase, expansion, and cracking of the slag aggregate. When this reaction occurs in road paving, cracking occurs. There have been a number of reported problems related to deterioration of road paving containing slow cooled steel slag aggregate which has resulted in restrictions on the use of steel slag [12]. 
Stabilization of EAF and BOF slag via atomization is demonstrated by the following.

Figure 3 shows the effect of atomization on the concentration of $\mathrm{CaO}$ in slag. The $\mathrm{X}$ ray diffraction (XRD) spectrums show a reference slow cooled EAF slag sample via conventional processing $(A)$ and an atomized sample $(B)$. The XRD spectrum for the slow cooled EAF slag sample, shown in Figure $3 A$, shows dicalcium ferrite $\left(2 \mathrm{CaO} \cdot \mathrm{Fe}_{2} \mathrm{O}_{3}\right)\left(\mathrm{C}_{2} \mathrm{~F}\right)$, hematite $\left(\mathrm{Fe}_{2} \mathrm{O}_{3}\right), \mathrm{C}_{2} \mathrm{~S}$, and $\mathrm{CaO}$. The $\mathrm{XRD}$ spectrum for the atomized EAF slag sample, shown in Figure $3 \mathrm{~B}$, shows $\mathrm{C}_{2} \mathrm{~F}, \mathrm{Fe}_{2} \mathrm{O}_{3}$, and $\mathrm{C}_{2} \mathrm{~S}$ are detected. Comparing Figures $3 \mathrm{~A}$ and $3 \mathrm{~B}$, we see that the $\mathrm{CaO}$ peaks are present in the slow cooled sample but absent in the atomized sample. The rapid quenching of atomization does not allow sufficient time for the transition of $\mathrm{C}_{3} \mathrm{~S}$ to form $\mathrm{CaO}$. The absence of free $\mathrm{CaO}$ in atomized slag allows for production of stable slag, permitting wider application for the atomized slag. As further examples of slag stability, the use of atomization has produced atomized EAF and BOF slags suitable for use as aggregate in asphalt concrete, construction concrete, polymer concrete, and highfriction road surfacing and bicycle paths.

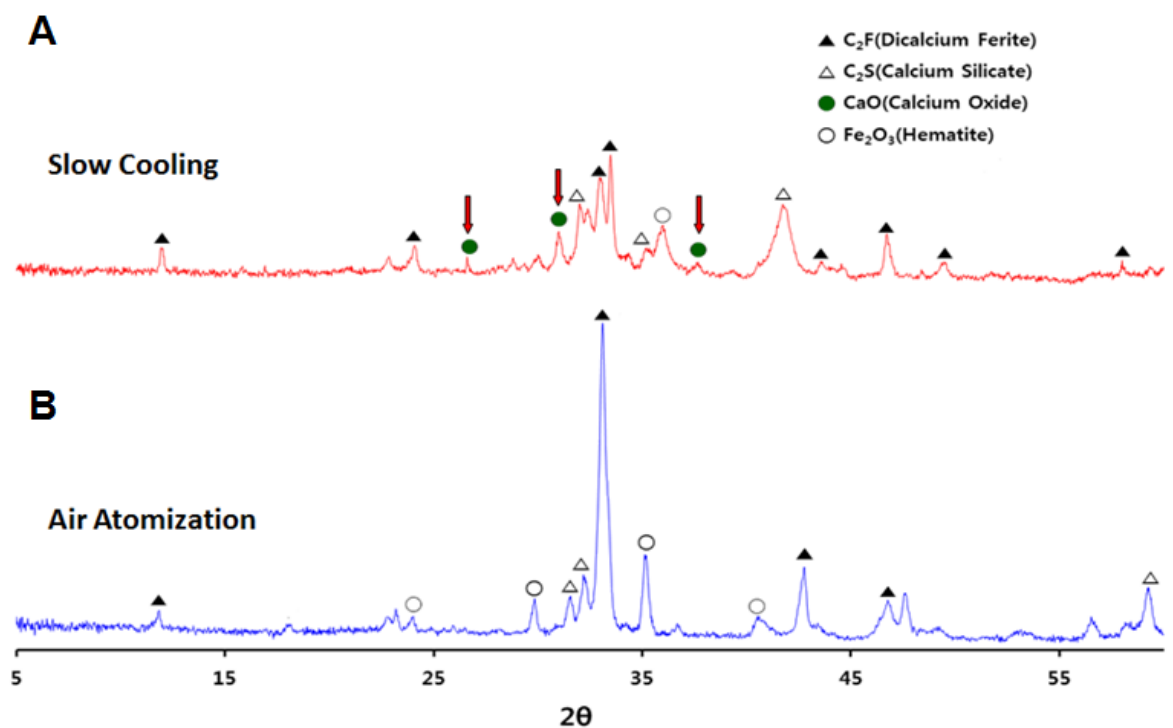

Figure 3. Comparison of X-ray diffraction patterns for EAF slag processed via slow cooling and air atomization.

\subsubsection{LMF Slags}

Similar to slow cooling of EAF and BOF slags, slow cooling of LMF slag also poses slag stability challenges. Conventional LMF handling practices are to dump and slow cool the slag. This leads to the generation of dust-prone LMF slag, which is not only an operational and environmental concern, but also results in limited use of the slag product. LMF slags typically contain dicalcium silicate $\left(\mathrm{Ca}_{2} \mathrm{SiO}_{4}\right)\left(\mathrm{C}_{2} \mathrm{~S}\right)$, which can be present in the slags in different phases, including $\alpha, \alpha^{\prime} H, \alpha^{\prime} L, \beta$, and $\gamma$. Under slow cooling process, $\alpha-C_{2} S$ undergoes a polymorphic solid-phase transition to $\beta-C_{2} S$, which then partially or fully transitions to $\mathrm{y}-\mathrm{C}_{2} \mathrm{~S}$. The difference in crystal structure and density between $\beta-C_{2} S$ and $y-C_{2} S$ results in high internal stress, causing disintegration of the slag into a powder and an accompanied volume increase $[13,14]$. However, rapid quenching freezes $C_{3} S$ and hence prevents formation of $C_{2} S$. Furthermore, even for the transformed fraction of $\mathrm{C}_{2} \mathrm{~S}$, the $\beta$ to $\gamma$ transformation can be avoided, hence expansion and decrepitation can be minimized [15-17].

Stabilization of LMF slag via atomization is demonstrated by the following. Figure 4 shows the effect of atomization on the concentration of $\mathrm{y}^{-} \mathrm{C}_{2} \mathrm{~S}$ in slag. The XRD 
spectrums show a reference slow cooled LMF slag sample via conventional processing $(A)$ and an atomization sample $(B)$. The XRD spectrum for the slow cooled LMF slag sample, shown in Figure $4 A$, shows mayenite $\left(C_{12} A_{7}\right)$, periclase $(\mathrm{MgO})$, and $\mathrm{y}-\mathrm{C}_{2} \mathrm{~S}$. The XRD spectrum of the atomized slag, shown in Figure $4 \mathrm{~B}$, shows $C_{12} A_{7}, M g O$, and $\beta-C_{2} S$. Comparing Figures $4 A$ and $4 B$, we see that $\gamma-C_{2} S$ is present in the slow cooled samples but absent in the atomized sample, and that $\beta-$ $\mathrm{C}_{2} \mathrm{~S}$ is present in the atomized sample (i.e. the transformation of $\beta-\mathrm{C}_{2} S$ to $\gamma-\mathrm{C}_{2} \mathrm{~S}$ did not occur in the atomized sample). By retaining the $\beta$ phase at room temperature, further transformation to the $Y$ phase is halted. While thermodynamically, the system still would find its lowest energy state in the $y$ phase, the quenching has resulted in a frozen material such that the kinetics of this transformation are slowed to rates that are not practically obtainable. For all practical purposes, the material can be considered stabilized in this $\beta$ phase. This modification, hence, prevents dusting of the atomized slag and permits new applications for the atomized slag. As further examples of slag stabilization, Ecomaister-Hatch has commercially produced from atomized LMF slags cement mixtures to produce rapid curing cement.

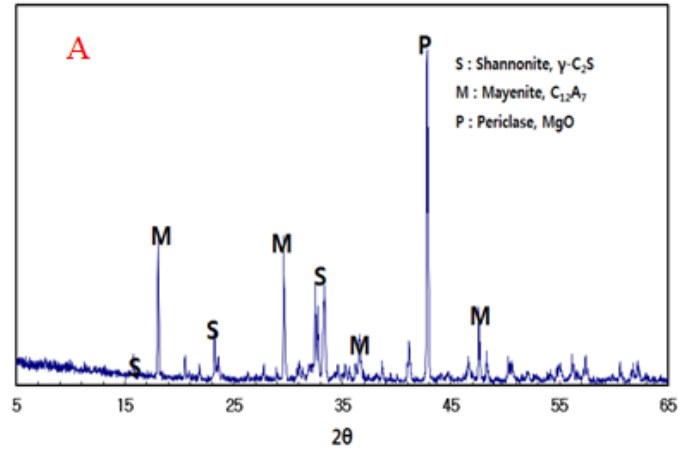

Slow Cooling

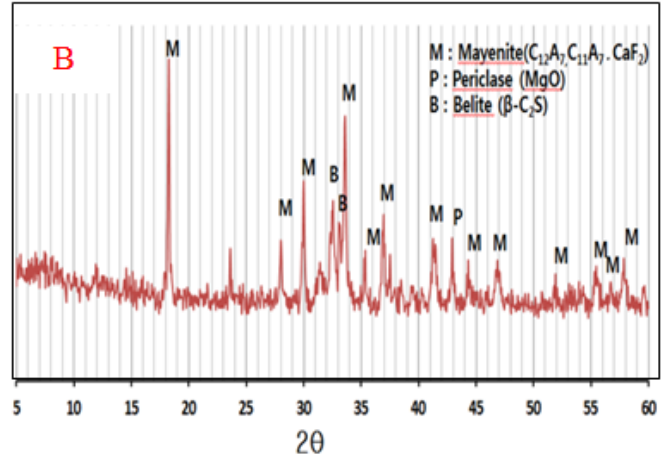

Air Atomization

Figure 4. XRD patterns of LMF slag processed via slow cooling and air atomization

\subsection{Immerging Research}

Although commercial implementation of atomization in the iron and steel industry has mainly been focused on EAF, BOF, and LMF slags, there is on-going research and development in its application in AOD and BF slags.

\subsubsection{AOD Slags}

Similar to LMF slags, AOD slags typically contains $\mathrm{C}_{2} \mathrm{~S}$ which undergoes a polymorphic solid-phase transition when slow cooled using conventional slag handling processes, leading to severe dust generation from disintegration. In labscale investigations, AOD slag was remelted and atomized using a lab-scale atomization unit. Figure 5 shows images of the atomized slag immediately after the process and after 10 days. As show, the slag does not disintegrate into dust after processing or even after aging for 10 days. The particles are hard and spherical. 


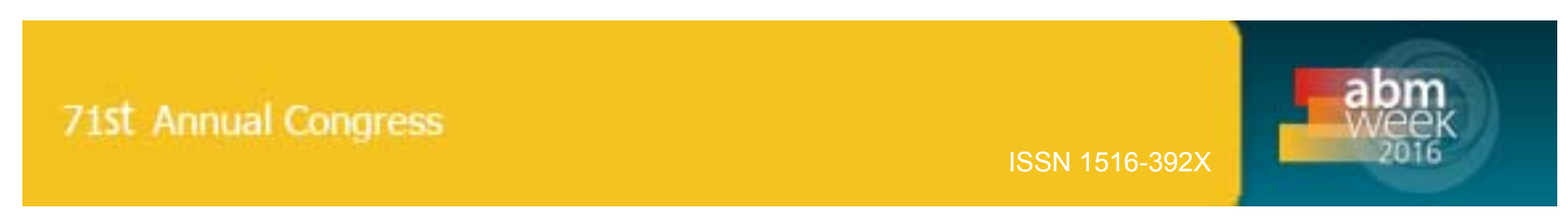

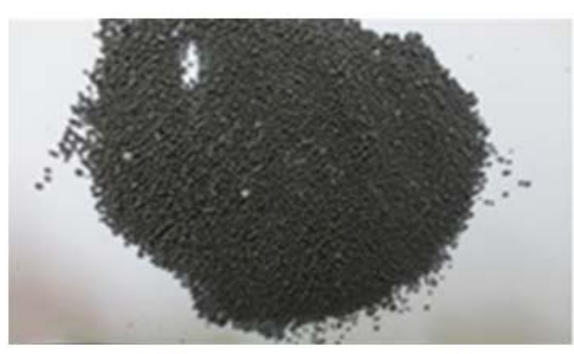

Immediately After Atomization

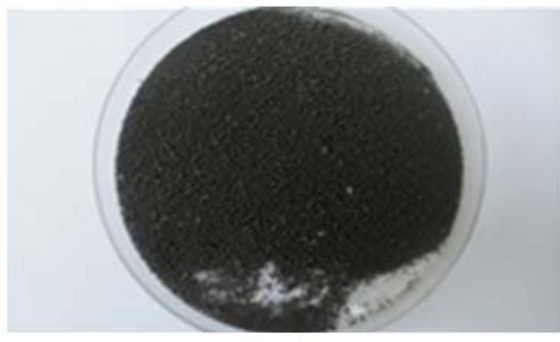

Aged 10 days

Figure 5. Air atomized AOD slag

Figure 6A shows the XRD spectrum of slow cooled $\mathrm{AOD}$ slag, where $\mathrm{MgO} \cdot \mathrm{SiO}_{2}$, merwinite (3CaO $\cdot \mathrm{MgO} \cdot 2 \mathrm{SiO}_{2}$ ), periclase (MgO), $\mathrm{y}-\mathrm{C}_{2} \mathrm{~S}$ and $\mathrm{MgO} \cdot \mathrm{Al}_{2} \mathrm{O}_{3}$ are detected. Figure $6 \mathrm{~B}$ shows that the only identified phase for the air atomized slag is merwinite. Stability of the atomized slag sample is attributed to the absence of $y-C_{2} S$. As discussed previously, rapid quenching prevents this phase transformation. These lab-scale results show promise that this technology will be applicable to AOD slag stabilization at full scale.
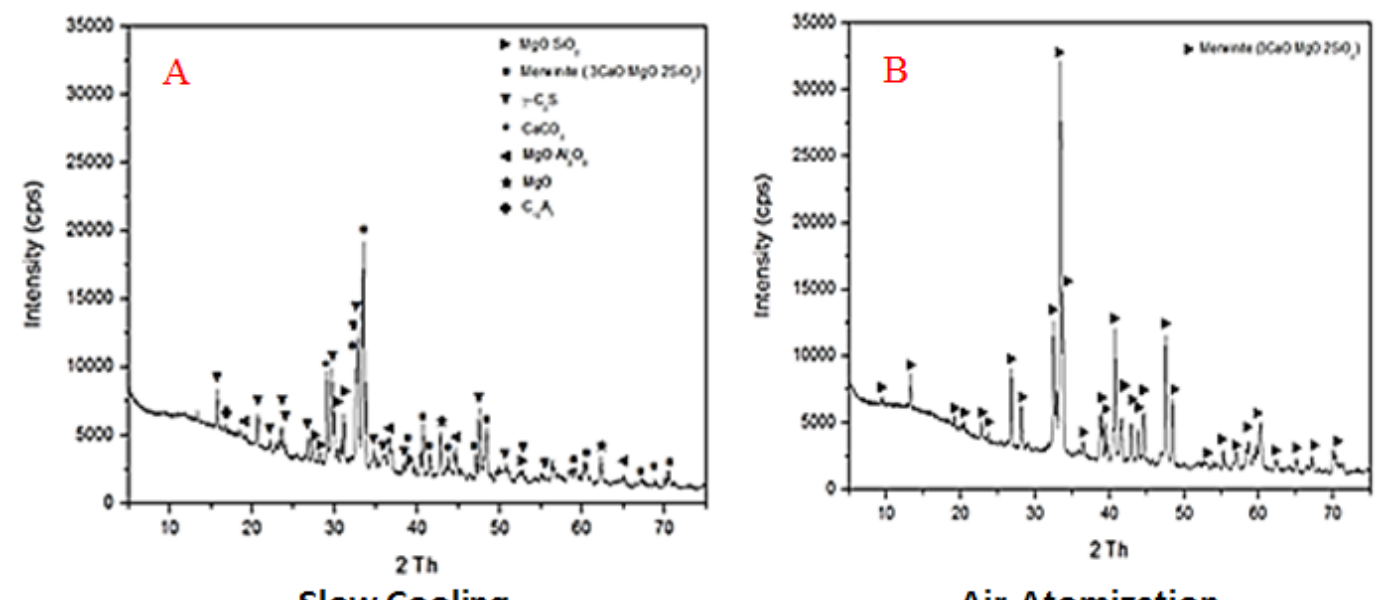

Slow Cooling

Air Atomization

Figure 6. XRD patterns of AOD slag processed via slow cooling and via air atomization

\subsubsection{BF Slags}

BF is generally treated via slow cooling or water granulation. In slow cooling, low value crystalline slag, which is generally used as aggregate, is produced. Granulation allows for rapid quenching of slag, thus producing glassy slag with $>90 \%$ glass content which when ground has cementitious properties, allowing for its use in high value application as a replacement for Ordinary Portland Cement (OPC) in the cement industry. The production of high glass content slag is critical for this application. This is evident from the recent developments of DSG technology for BF slag, as discussed in Section 2.3, which strives for production of BF slag with high glass content.

In lab-scale atomization investigations, BF slag was remelted and atomized using a lab-scale atomization unit. An example of atomized BF slag is shown in Figure $2 \mathrm{~b}$. XRD pattern of the atomized slag, shown in Figure 8, indicates a high glass content of $98 \%$. In additional, compressive strength of cement admixtures with slag replacement was studied. Figure 9 shows the compressive strength development of three cement sample: (1) $100 \%$ OPC, (2) $20 \%$ replacement of OPC with ground water granulated slag, and (3) $20 \%$ replacement of OPC with ground atomized slag. 
At 28 days under both moist-curing and dry air curing conditions, samples with $20 \%$ OPC replacement with atomized slag had similar performance as samples with $20 \%$ replacement with water granulated slag. It is evident that both glass content and compressive strength properties of samples with atomized slag are comparable to samples with water granulated slag, indicating that atomization may be a safer and more sustainable alternative to water granulation for the production of rapidly quenched glassy BF slag applicable for the cement industry.

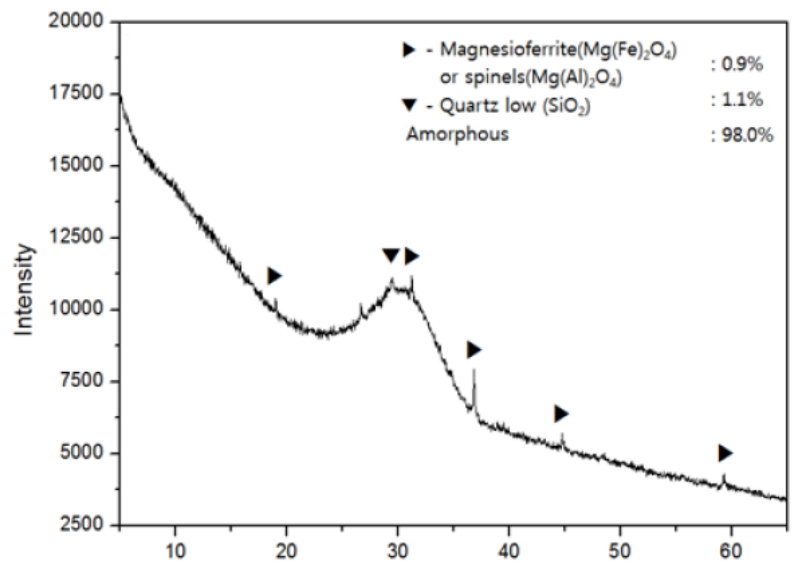

Figure 8. XRD pattern of BF slag processed using air atomization

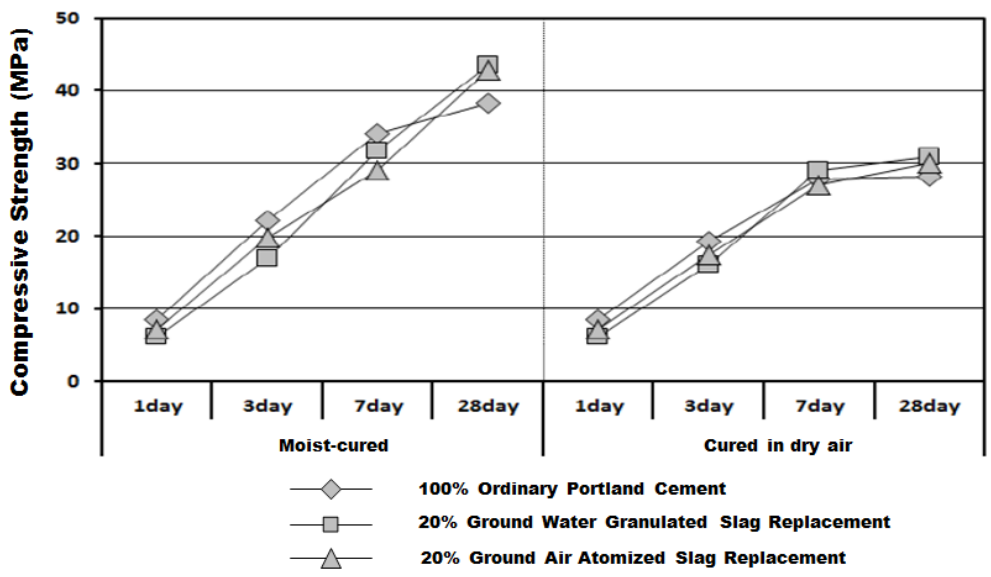

Figure 9. Compressive strength of cement admixtures with 100\% OPC, $20 \%$ ground water granulated slag/ $80 \%$ OPC, and $20 \%$ ground air atomized slag/80\% OPC.

\section{CONCLUSIONS}

Currently, conventional slag handling methods in the iron and steel industry continues to involve slag dumping for EAF, BOF, AOD, LMF, and BF slags, and wet granulation for BF slags. While wet granulation is not applicable to EAF, BOF, LMF, and AOD slags due to their high metal contents and thus explosion risk, dry granulation is feasible. Dry slag granulation offers substantial safety benefits as it eliminates one of the key elements that can combine with slag to create explosions, water. Further, dry slag granulation improves sustainability in slag handling, by reducing environmental contamination and increasing resource conservation by allowing for production of high value by-products and slag heat recovery. In recent years, the industry has witnessed a progressing shift towards developing and piloting dry slag granulation systems. Of the various dry slag granulation technologies 
reviewed, the only technology adopted at industrial scale has been air atomization technology. Air atomization offers a simple, robust, and proven platform for the treatment of EAF, BOF, and LMF slags, and there is on-going developments showing promise for the application of atomization for the treatment of AOD and BF slags.

\section{REFERENCES}

1 Occupational Safety \& Health Administration. Accident: 200962603 - Employee Injured When Hot Slag Explodes After Striking Water. Trans [internet]; January 3, 1999 [cited March 20, 2015]. Available:

https://www.osha.gov/pls/imis/accidentsearch.accident detail?id=200962603.

2 Malman, S. J. East Chicago Steel Plant Explosion Injures Three Workers. Trans [internet]; February 24, 2009 [cited March 20, 2016]. Available: http://www.chicagoworkerscompensationlawyerblog.com/2009/02/east chicago steel p lant accid.html

3 Holecek, A. Accident at East Chicago steel plant under investigation. Trans [internet]; February 16, 2009 [cited March 20, 2016]. Available: http://www.nwitimes.com/news/local/accident-at-east-chicago-steel-plant-underinvestigation/article 6a164db9-8b09-5620-9506-b14934ab7e24.html

4 Business Standard. Bhushan Steel's killer blast furnace sealed. Trans [internet]; November 14, 2013 [cited March 20, 2016]. Available: http://www.businessstandard.com/article/companies/bhushan-steel-s-killer-blast-furnace-sealed113111401153 1.html

5 Mishra, S. Blast at Bhushan steel plant kills one. Trans [internet]; November 14, 2013 [cited March 20, 2016]. Available:

http://timesofindia.indiatimes.com/city/bhubaneswar/Blast-at-Bhushan-steel-plant-killsone/articleshow/25725276.cms

6 Baosteel Engineering. Baosteel Engineering. Trans [internet]; [cited March 26, 2016]. Available: http://www.baosteelengineering.com/en/pdf/BSSF.pdf

7 World Steel Association. Baosteel: Steelmaking slag treatment saves space, dust emissions and energy. Trans [internet]; [cited March 26, 2016]. Available: http://www.worldsteel.org/dms/internetDocumentList/downloads/steel-bytopic/sustainability/Slag-treatmentBaosteel/document/Slag\%20treatment\%20Baosteel.pdf

8 Michels, D. \& Kappes, H. Dry slag granulation with energy recovery: Operation of full scale pilot plant. European Metallurgical Conference 2015, 2015; 2: 1027-1039.

9 McDonald, I., \& Werner, A. Dry slag granulation with heat recovery. AISTech 2014 Proceedings, 2014.

10 Jahanshahi, S., \& Xie, D. Current status and future direction of CSIRO's dry slag granulation process with waste heat recovery. 5th International Congress on the Science and Technology of Steelmaking 2012, 2012.

11 CSIRO. Forging a future in green steelmaking. Trans [internet];March 16, 2015 [cited March 26, 2016] Available: http://www.csiro.au/en/News/News-releases/2015/Dry-slaggranulation

12 Federal Highway Administration Research and Technology. User Guidelines for Waste and Byproduct Materials in Pavement Construction (Publication Number: FHWA-RD-97148). Trans [internet]; [cited March 14, 2016]. Available:

https://www.fhwa.dot.gov/publications/research/infrastructure/pavements/97148/059.cf $\underline{\mathrm{m}}$.

13 Kim, Y., Nettleship, I., and Kriven, W. Phase transformations in dicalcium silicate: II, TEM studies of crystallography, microstructure, and mechanisms, Journal of the American Ceramic Society. 1992; 75: 9: 2407-2419.

14 Serjun, V. Z. , Mirti, B., and Mladenovi, A. Evaluation of ladle slag as a potential material for building and civil engineering, Materials and technology. 2013; 543-550. 
15 Chan, C., Kriven, W., and Young, J. Physical stabilization of the beta to gamma transformation in dicalcium silicate, Journal of the American Ceramic Society. 1992; 75: 6: $1621-1627$.

16 Durinck, D., Engström, F., Arnout, S., Heulens, J., Jones, P., Björkman, B. B. B., and Wollants, $\mathrm{P}$. Hot stage processing of metallurgical slags, Resources, Conservation and Recycling. 2008; 52: 10: 1121-1131.

17 Seki, A., Aso, Y., Okubo, M., Sudo, F. , and Ishizaka, K. Development of dusting prevention stabilizer for stainless steel slag, Kawasaki Steel Technical Report. 1986; 15: 16-21. 